https://nv.nltu.edu.ua

https://doi.org/10.36930/40300221

$@ \bowtie$ Correspondence author

Article received 07.04.2020 p.

Article accepted 04.06.2020 p.

O. T. Velyka

veloks@ukr.net

UDC 621.9:048.6

Д. П. Ребот, В. Г. Топільницький, О. Т. Велика

Національний університет "Львівська політехніка", м. Львів, Украйна

\title{
ДОСЛІДЖЕННЯ ЗМІНИ АМПЛІТУДИ ТА ЧАСТОТИ КОЛИВАНЬ СИПКОГО МАТЕРІАЛУ В ПРОЦЕСІ ВІБРАЦІЙНОЇ СЕПАРАЦІЇ
}

\begin{abstract}
Здійснено огляд попередніх досліджень впливу внутрішніх і зовнішніх параметрів процесу вібраційної сепарації на його ефективність. Визначено, що на процес сепарації впливають не тільки параметри вібраційного сепаратора, а й характеристики сипкого матеріалу та характер його руху на ситі. Встановлено, що всі дослідження розглядають окремі випадки руху сипких матеріалів або їх частинок під час сепарування та не відображають цей процес у повному обсязі. Враховуючи, що під час вібраційної сепарації сипкий матеріал здійснює на ситі вібраційного сепаратора складний просторовий рух, його неможливо описати однією математичною моделлю. Тому кожен із досліджених випадків характеризує можливий вплив, як фізичних процесів у сипкому матеріалі, так і режимів їх руху на процес сепарування. Як окремий випадок, у роботі розглянуто вплив консервативних коливань сипкого матеріалу. Досліджено вплив залежності зміни частоти, амплітуди та періоду коливань сипкого матеріалу в процесі вібраційної сепарації. Побудовано математичну модель, на підставі якої виконано дослідження залежності зазначених вище параметрів під час руху сипкого матеріалу вздовж сита вібраційного сепаратора. Під час розв'язування нелінійні пружні властивості шару матеріалу апроксимувались деякою степеневою залежністю, за допомогою диференціальних рівнянь. У ході досліджень визначено, що перевантаження сепаратора та зменшення пружних властивостей шару сипкого матеріалу призводить до зменшення амплітуди коливань. Для м'яких систем зростання амплітуди веде до спадання частоти коливань, а для жорстких зі зростанням амплітуди період коливань зростає. За однакових значень амплітуди частота коливань буде менша для жорстких систем. Отримані результати дають змогу впливати на ефективність сепарації шляхом зміни амплітуди та частоти коливань шару сипкого матеріалу, а також, коригуванням навантаження на сито сепаратора, залежно від характеристик шару сепарованого матеріалу. Надалі їх можливо застосовувати у сепараторах та конвеєрах із горизонтальним розміщенням робочого органу.
\end{abstract}

Ключові слова: вібрація; математична модель; сито; ефективність; шар завантаження.

Вступ. Вібраційні сепаратори, грохоти, сортувальні машини та центрифуги мають надзвичайно широке застосування у всіх галузях промисловості, виконуючи сортування (за величиною, густиною і т.ін.) різноманітних продуктів. Розділення продуктів виробництва і сировини на сорти або фракції може мати попередній, проміжний чи остаточний характер, коли отримана фракція є готовим продуктом. Попереднє сортування використовують для видалення із продуктів виробництва або сировини тих відходів, домішок чи сортів, котрі не повинні надходити у подальшу технологічну обробку [5]. Проміжне сортування проводять 3 метою, наприклад, контрольного дослідження продукції чи дозування [1].

Ефективність та продуктивність сепарації значною мірою залежить від таких механічних та технологічних факторів, як: форма частинок, гранулометричний склад, вологість сипкого середовища, співвідношення діаметра частинки сипкого матеріалу, яка надходить на сепа- рацію, до діаметра отворів у ситі, конструкційних параметрів сепаратора, товщини шару сипкого матеріалу на ситі сепаратора, режиму роботи установки та інших показників. Проте, не враховуючи розходжень у механічних та технологічних параметрах під час сепарації сипкого середовища, для всіх випадків наявна загальна залежність продуктивності та ефективності сепарації від тривалості просіювання: у перших проміжках часу сепарації вони зростають дуже швидко, але потім їх приріст сповільнюється. Таку залежність ефективності сепарації від тривалості просіювання можна пояснити тим, що в перший період часу через отвори сита проходять менші частинки. У подальшому на ситі кількість малих частинок сипкого матеріалу зменшується і залишаються тільки великі частинки, які потребують більше часу для того, щоб пройти через отвори сита.

Окрім цього, під час просіювання (розділення) у сипкому середовищі, що залишається на ситі, зростає кількість частинок, які забивають отвори в ситі та пе-

Інформація про авторів:

Ребот Дарія Петрівна, канд. техн. наук, асистент, кафедра проектування та експлуатації машин. Email: dariiarebot@gmail.com; https://orcid.org/0000-0002-3583-0800

Топільницький Володимир Григорович, канд. техн. наук, доцент, кафедра проектування та експлуатації машин. Email: topilnvol@gmail.com; https://orcid.org/0000-0002-5191-326X

Велика Оксана Тарасівна, канд. техн. наук, доцент, кафедра проектування та експлуатації машин. Email: veloks@ukr.net; https://orcid.org/0000-0003-1575-8829

Цитування за Дсту: Ребот Д. П., Топільницький В. Г., Велика О. Т. Дослідження зміни амплітуди та частоти коливань сипкого матеріалу в процесі вібраційної сепарації. Науковий вісник НлтУ України. 2020, т. 30, № 2. С. 118-121.

Citation APA: Rebot, D. P., Topilnytskyy, V. H., \& Velyka, O. T. (2020). Research of amplitude and frequency oscillations change in bulk material during the vibrating separation process. Scientific Bulletin of UNFU, 30(2), 118-121. https://doi.org/10.36930/40300221 
решкоджають просіюванню сипкого середовища [4]. Мала кількість великих та важко прохідних частинок у завантаженому матеріалі забезпечує легкий процес сепарування та його високу ефективність. Також зі збільшенням навантаження на сепаратор ефективність сепарації знижується [2]. Це пов'язано з тим, що шар сипкого середовища на ситі сепаратора досягає значної товщини і внаслідок цього весь сипкий матеріал сходить зі сита, розрихлення та розшарування в ньому не відбувається. Шарам середовища, які містяться вгорі, важко пройти крізь нижні шари до отворів сита. Як наслідокпроцес сепарації відсутній і сепаратор перетворюється на транспортувальний пристрій. Враховуючи, що висота шару сипкого середовища залежить від навантаження вихідного матеріалу, то збільшення навантаження призводить до зростання шару сипкого матеріалу та зниження ефективності сепарації. Зменшення навантаження до критичної межі також призводить до зниження ефективності сепарації. У разі малого навантаження сепаратора, частинки середовища здійснюють стрибкоподібний рух, внаслідок чого кількість їх зіткнень із ситом значно зменшується. Вплив навантаження на ефективність сепарації визначається такими факторами: характеристиками вологості, величини, форми матеріалу, наявності в ньому великих і налипаючих частинок, кута нахилу та довжини робочого контейнера, розміру отворів в ситі та ін. На практиці ефективність сепарації регулюють шляхом зміни кута нахилу сита, форми та розмірів отворів, зміною амплітуди коливання.

Усі фактори, які впливають на основні технологічні показники процесу вібраційної сепарації (ефективність та продуктивність), поділяють на дві основні групи: фізико-механічні властивості сипкого матеріалу (густина, вміст домішок, вологість, гранулометричний склад) та конструктивно-механічні характеристики сепаратора (розмір отворів сита та його кут нахилу до горизонту, амплітуда коливань робочого контейнера). Тобто ці показники залежать не тільки від конструктивних параметрів вібраційного сепаратора, але й від характеристик сипкого матеріалу, що призводить до необхідності їх дослідження та врахування.

Об'єктом дослідження є шар сипкого матеріалу на ситі вібраційного сепаратора.

Предметом дослідження є методи і засоби, які дадуть змогу встановити зміни амплітудо-частотних характеристик шару завантаження сипкого матеріалу під час процесу його сепарування.

Метою дослідження є визначення зміни частоти й амплітуди коливання шару сипкого матеріалу для можливості підвищення ефективності вібраційної сепарації, шляхом математичного моделювання.

Завданням дослідження є побудова математичної моделі руху шару сипкого матеріалу та графічних залежностей для огляду зміни його частоти та амплітуди залежно від коефіцієнта, що враховує пружні властивості шару завантаження.

Наукова новизна результатів дослідження полягає в тому, що під час моделювання шару сипкого середовища у вигляді пружної бали вперше побудовано математичну модель руху шару сипкого матеріалу, яка дає змогу дослідити його зміну частоти та амплітуди залежно від коефіцієнта, що враховує пружні властивості шару завантаження.

Практична значущість отриманих результатів може бути отримана внаслідок визначення основних по- казників динаміки шару сипкого матеріалу під час сепарування для подальшого регулювання ефективності процесу розділення.

Аналіз літературних джерел. Вплив вібрації на рух сипкого середовища дослідив Голованевський [3]. У його дослідженнях описано різні режими руху сипких матеріалів під дією вібрації, зокрема такі, як віброкипіння, віброущільнення та віброзависання. На підставі проведених досліджень визначено, що для забезпечення максимальної ефективності розділення сипких матеріалів під дією вібрації, потрібно вибирати амплітуду та частоту вібрацій на підставі вібраційного коефіцієнта перевантаження. Також досліджено різні типи руху сипкого середовища під дією вібрацій, зокрема: періодичний рух, біфуркаційний рух, хаотичний рух. У роботі [9] автор дослідив рух окремої частинки сипкого середовища на ситі вібраційного зворотно-поступального сепаратора. Визначено, що хаотичний рух частинок $є$ корисним для процесу сепарування та сприяє пришвидшенню просіювання. На підставі нелінійного закону створено модель руху частинки по ситу сепаратора та розглянуто різні типи іiі руху. У роботі $[10,11]$ автор дослідив рух частинки сипкого середовища у вібросепараторах 3 круговою вібрацією. Проведені експерименти із різними формами частинок середовища. Проаналізовано рух частинок, їх швидкість вздовж сита вібраційного сепаратора та вплив кута нахилу сита на ефективність сепарації. У роботах $[7,8]$ автор розглянули шар сипкого середовища на ситі вібраційного сепаратора як нашарування плоских пружно-пластичних балок. На підставі цих припущень проведено математичне моделювання руху сипкого середовища за умови вертикальних та горизонтальних коливань руху сита вібраційного сепаратора. Розглянуто окремі випадки впливу параметрів сипкого середовища на інтенсивність його сепарації.

Огляд літератури підтверджує, що процес вібросепарації сипких середовищ є доволі складним та не може бути описаний на підставі одного чи декількох припущень. Розглянуто окремі випадки руху сипкого середовища на ситі вібраційного сепаратора та впливу зовнішніх і внутрішніх чинників на процес сепарації. На підставі наведеного вище, варто зазначити, що ці дослідження потребують подальшого розширення для визначення оптимальних режимів сепарування. Важливо продовжити дослідження впливу амплітуди та частоти коливань сипкого матеріалу на інтенсивність процесу сепарування. Це дасть змогу розширити можливості регулювання параметрів процесу сепарації для підвищення його ефективності.

Матеріал та методи дослідження. Продовжуючи попередні дослідження $[7,8]$, пропонуємо розглянути метод Ван-дер-Поля для створення математичної моделі руху сипкого середовища. Рівняння поздовжніх коливань шару матеріалу на горизонтально розташованому ситі має розв'язки, які можна описати через періодичні Ateb-функції. При цьому сили тертя не враховують. За умови, що

$$
u_{t t}-\alpha^{2}\left(u_{x}\right)^{v} u_{x x}=0,
$$

де: $\alpha$ - стала, $v$ - степінь нелінійності пружних властивостей шару матеріалу, виражається формулою

$$
v_{i}=\left(2 \mu_{i}+1\right)\left(2 \mu_{i}^{* *}+1\right)^{-1} \text {, де } \mu_{i}, \mu_{i}^{* *}=0,1,2, \ldots, i=1,2,0 \leq x \leq l .
$$


Для наведеного вище рівняння розглядають однорідні крайові умови

$$
\left.u(x, t)\right|_{x=0}=\left.u(x, t)\right|_{x=0}=0 .
$$

Рівняння (1) попередньо досліджували в роботі [6], де показано, що воно має періодичні по обох змінних розв'язки. Незважаючи на те, що рівняння (1) $є$ нелінійним, для його інтегрування можна застосовувати метод відокремлення змінних. Тобто, при підстановці його розв'язку у вигляді

$$
u(x, t)=\bar{X}(x) \cdot \bar{T}(t),
$$

для знаходження невідомих функцій $\bar{X}(x)$ і $\bar{T}(t)$ отримаємо звичайні нелінійні диференціальні рівняння:

$$
\begin{gathered}
\frac{d^{2} \bar{X}}{d x^{2}}\left(\frac{d \bar{X}}{d x}\right)^{v}+\lambda \bar{X}(x)=0, \\
\frac{d^{2} \bar{T}}{d t^{2}}+\alpha^{2} \lambda \bar{T}^{v+1}(t)=0,
\end{gathered}
$$

де $\lambda$ - невідомий параметр, який буде із крайових умов (1).

Лінійно незалежні розв'язки рівняння (4) отримаємо за допомогою періодичних Ateb-функцій у вигляді:

$$
\bar{X}(x)=X_{0}\left\{\begin{array}{l}
s a\left(1, \frac{1}{v+1},\left(\lambda \frac{v+2}{2 X_{0}^{v}}\right)^{\frac{1}{v+2}} x\right) \\
c a\left(1, \frac{1}{v+1},\left(\lambda \frac{v+2}{2 X_{0}^{v}}\right)^{\frac{1}{v+2}} x\right)
\end{array}\right\}
$$

Із крайової умови (1) отримуємо значення параметра $\lambda$ та відповідно функцію $\bar{X}(x)$ :

$$
\begin{gathered}
\lambda_{k}=\frac{2 X_{0}^{v}}{v+2}\left(\prod \frac{k}{l}\right)^{v+2}, \\
\bar{X}(x)=X_{0} \operatorname{sa}\left(1, \frac{1}{v+1}, \prod \frac{k}{l} x\right),
\end{gathered}
$$

де: $X_{0}$ - стала; $k=1,2,3, \ldots, \Pi=\prod\left(1, \frac{1}{v+1}\right)$.

Розв'язками нелінійного рівняння (5) є також система лінійно незалежних Ateb-функцій:

$$
\bar{T}(t)=T_{0}\left\{\begin{array}{c}
c a\left(v+1,1,\left(\frac{v+2}{2} \alpha^{2} \lambda_{k} T_{0}^{v}\right)^{\frac{1}{2}} t\right), \\
s a\left(v+1,1,\left(\frac{v+2}{2} \alpha^{2} \lambda_{k} T_{0}^{v}\right)^{\frac{1}{2}} t\right),
\end{array}\right\}
$$

де $T_{0}$ - довільна стала.

Характерною особливістю отриманих функцій є те, що у загальному випадку коефіцієнти при незалежних змінних $x$ i $t$ у них $є$ також функціями сталих параметрів $X_{0}$ і $T_{0}$. Підставляючи у (9) замість параметра $\lambda_{k}$ його значення для розглядуваних крайових умов відповідно до (7), отримаємо

$$
\bar{T}(t)=T_{0}\left\{\begin{array}{l}
c a\left(v+1,1, \omega_{k}\left(a_{k} t\right)\right), \\
s a\left(v+1,1, \omega_{k}\left(a_{k} t\right)\right),
\end{array}\right\}
$$

$$
\omega_{k}(a)=\alpha a^{\frac{v}{2}}\left(\frac{k \Pi_{x}}{l}\right)^{\frac{v+2}{2}} .
$$

Отже, одночастотні поздовжні коливання шару матеріалу у процесі вібросепарації на горизонтально розташованому ситі описуються такою залежністю:

$$
u_{k}(x, t)=a s a\left(1, \frac{1}{v+1}, \Pi_{x} \frac{k}{l} x\right) c a\left(v+1,1, \omega_{k}(a) t\right),
$$

де $a=X_{0} T_{0}$. Нижче називатимемо параметр $a$ амплітудою $\left(a=\max u_{k}(x, t)\right)$, а $\omega_{k}(a)$ - частотою коливань системи. Як окремий випадок із отриманого при $v=0$ маємо одночастотні поздовжні коливання лінійної моделі сипкого середовища, частота якого вже не залежить від амплітуди процесу.

У формулі (12) нижче будемо вибирати для функції $\bar{T}(t)$ косинус Ateb-функцію, тобто перше зі співвідношень у формулі (11), що відповідає умові максимального початкового відхилення сипкого середовища від рівноважного положення. Отримані результати одночасно і визначають період коливань сипкого середовища

$$
T=\frac{2 \sqrt{\pi} \Gamma\left(\frac{1}{v+2}\right)}{\alpha \Gamma\left(\frac{1}{2}+\frac{1}{v+2}\right)} \cdot\left[\frac{l \Gamma\left(\frac{1}{2}+\frac{v+1}{v+2}\right)}{\sqrt{\pi} \Gamma\left(\frac{v+1}{v+2}\right)}\right]^{1+\frac{v}{2}} a^{-\frac{v}{2}} .
$$

Нижче на графіках подано залежності періоду коливань від амплітуди (рис. 1) та періоду коливань від параметра $v$ (рис. 2) для м'яких $(-1<v<0)$, лінійних $(v=0)$ та жорстких систем $(v>0)$.

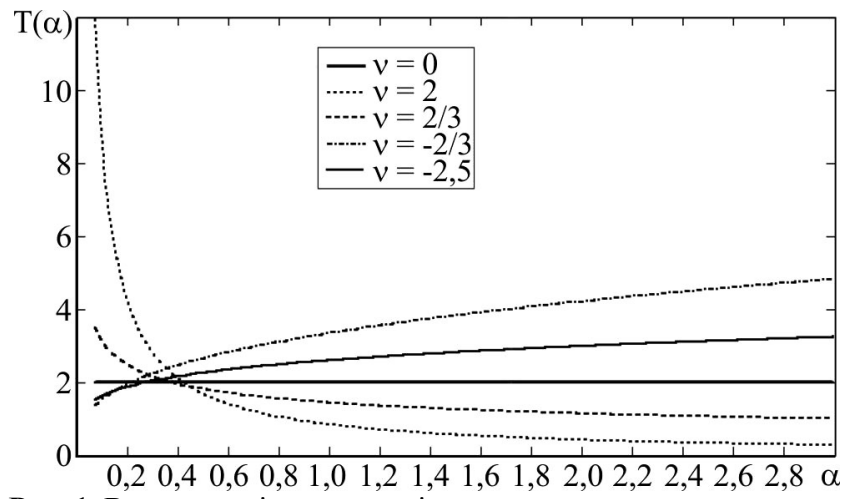

Рис. 1. Вплив амплітуди на період коливань шару сипкого матеріалу при деяких значеннях параметра $\mathrm{v}$

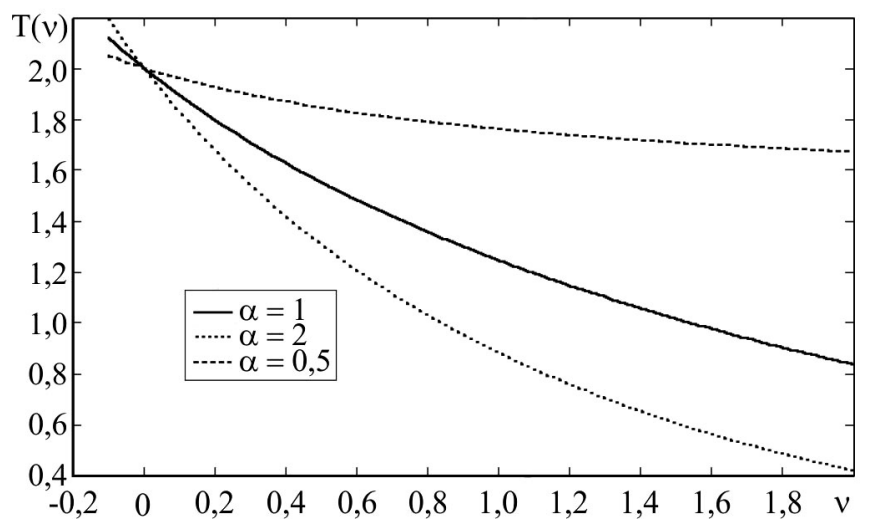

Рис. 2. Вплив параметра v на період коливань шару матеріалу при деяких значеннях амплітуди

Із одержаних графічних залежностей випливає:

a) у випадку $-1<v<0$ із зростанням амплітуди коливань шару сипкого матеріалу $a$ період його коливань зростає 
і навпаки, якщо характеристика шару матеріалу середовища така, що $v>0$, то із зростанням амплітуди $a$ період коливань його спадає;

б) наведене вище потрібно використовувати у сепаратоpax iз горизонтальним розміщенням сит, адже із періодом (частотою) коливань сипкого середовища зв'язаний процес вібросепарації. Для більших частот коливань середовища інтенсивність останньої зростає;

в) якщо $v>0$, то періодичні Ateb-функції у співвідношеннях (1)-(9) перетворюються у звичайні тригонометричні функції, а період динамічного процесу у сипкому середовищі (лінійна модель) не залежить від його амплітуди.

г) для сипких середовищ, амплітуди коливань яких однакові, частота коливань більша у того, у якому відповідає менше значення параметра $v$.

Висновки. Отримані результати дають змогу проводити регулювання процесу сепарації з метою підвищення його ефективності. Залежності слугують базою для подальшого дослідження впливу нелінійних сил тертя та швидкості руху шару матеріалу на процес сепарування. Дані дослідження також можуть бути використані в процесах вібротранспортування та віброоброблення.

\section{References}

1. Besenhard, M. O., Faulhammer, E. et al. (2015). Accuracy of micro dosing via a vibratory sieve-chute system. European Journal of Pharmaceutics and Biopharmaceutics, 94, 264-272 https://doi.org/10.1016/j.ejpb.2015.04.037

2. Diaz-Zorita, M., Grove, J. H., \& Perfect, E. (2007) Sieving duration and sieve loading impacts of dry soil fragment size distribution. Soil and Tiillage Research, 94(1) 15-20. https://doi.org/10.1016/j.still.2006.06.006
3. Golovanevskiy, V. A., Arsentyev, V. A., Blekhman, I. I. et al. (2011) Vibration-Induced phenomena in bulk granular materials. International Journal of Mineral Processing, 100(3-4), 79-85. https://doi.org/10.1016/j.minpro.2011.05.001

4. Hudson, R. B., Jansen, M. L., \& Linkson, P. B. (1969) Batch sieving of deep particulate beds on a vibratory sieve. Powder Technology, 2(4) 229-240. https://doi.org/10.1016/0032$\underline{5910(69) 80017-3}$

5. Ray Singh. (2004) Vibratory separators still make the grade for screening dry bulk powders. Filtration and Separation, 41(1), 2021. https://doi.org/10.1016/S0015-1882(04)00107-7

6. Rebot, D. P. (2012) Metodyka vyznachennia osnovnykh fizykomekhanichnykh kharakterystyk sypkykh seredovyshch. Scientific Bulletin of UNFU, 22(6), 114-119. [In Ukrainian].

7. Rebot, D. P., \& Topilnytskyi, V. H. (2018) Matematychna model vyznachennia zminy amplitudy ta chastoty kolyvannia sypkoho materialu v protsesi vibroseparatsii. Scientific Bulletin of UNFU, 28(2), 164-166. https://doi.org/10.15421/40280231

8. Topilnytskyy, V., Rebot, D. et al. (2017) Modeling the dynamics of vibratory separator of the drum type with concentric arrangement of sieves. Eastern-European Journal of Enterprise Technologies, 2/7(86), 26-34. https://doi.org/10.15587/17294061.2017.95615

9. Wang, L., Ding, Z., et al. (2017) Kinematics and dynamics of a particle on a non-simple harmonic vibrating screen. Particuology, 32, 167-177. https://doi.org/10.1016/j.partic.2016.11.002

10. Zhao, L., Lui, Ch., et al, (2011) Simulation of the screening processon a circularly vibrating screen using 3D-DEM. Mining Science and Technology (China), 21(5), 677-680. https://doi.org/10.1016/i.mstc.2011.03.010

11. Zhao, L., Zhao, Y., et al. (2016) Laboratory-scale validation of a DEM model of screening processes with circular vibration. $M i-$ ning Science and Technology (China), 20(2), 276-280. https://doi.org/10.1016/j.powtec.2016.09.034

D. P. Rebot, V. H. Topilnytskyy, O. T. Velyka

Lviv Polytechnic National University, Lviv, Ukraine

\section{RESEARCH OF AMPLITUDE AND FREQUENCY OSCILLATIONS CHANGE IN BULK MATERIAL DURING THE VIBRATING SEPARATION PROCESS}

In the process of vibration separation, the bulk loading layer makes complex spatial movement in the working container. That's why, it cannot be described using a single mathematical model. Previous investigations have described the movement of a single particle of bulk material in the reciprocating motion of the sieves, the movement of the layer of bulk material under the action of vibration, particular types of movement of the layer of bulk material during the vertical and horizontal vibrations of the separator. It is established that the efficiency of separation depends not only on the parameters of the vibrating separator, but also on the characteristics of the bulk medium. Accordingly, each individual, investigational case allows increasing the efficiency of separation by regulating them. A special case of conservative fluctuations of the bulk material along the sieve of the vibrating separator is considered. The influence of dependence of changing amplitude, frequency and oscillation period of bulk material in the process of vibration separation is conducted. A mathematical model of the movement of bulk material along a sieve of a vibrating separator is constructed. When solving, the nonlinear elastic properties of the material layer were approximated by some degree of dependence, using differential equations. In the course of the researches it was determined that the overload of the separator and reduction of the elastic properties of the layer of bulk material leads to a decrease in the period of oscillation and the amplitude of oscillation. For soft systems, the amplitude increase leads to an increase in the oscillation period, and for the rigid amplitude increase the oscillation period decreases. With the same amplitude values, the oscillation frequency will be smaller for rigid systems. The results obtained influence the separation efficiency by varying the amplitude and frequency of oscillation of the bulk material, as well as by adjusting the load on the separator sieve, depending on the characteristics of the separating material layer. Dependencies obtained can be the basis for further studies of the movement of bulk material in a vibrating separator, subject to different variable speeds of its motion.

Keywords: vibration; mathematical model; sieve; efficiency; loading layer. 